\title{
STUDI PULAU PANAS PERKOTAAN DAN KAITANNYA DENGAN PERUBAHAN PARAMETER IKLIM SUHU DAN CURAH HUJAN MENGGUNAKAN CITRA SATELIT LANDSAT TM STUDI KASUS DKI JAKARTA DAN SEKITARNYA
}

\author{
Halda Aditya*, Sri Lestari**, Hilda Lestiana***
}

\begin{abstract}
Heat island was a phenomenon where the temperature of air in one region higher than the temperature of the open air around it. Urban areas often had the temperature higher 1-6 Celsius when compared the area of surrounding area (the area of outskirts/rural). This phenomenon that was known as "Pulau Panas Perkotaan" or "Urban Heat Island" (UHI). This Research aimed to knowing influence of the heat islands of urban areas to climate parameter especially the temperature and the rainfall in the Jakarta and surrounding area. Data used in this research was rainfall data and daily air temperature from 5 climate observation stations, within time period from January 1991 to December 2001 as the surface data. The Landsat satellite image 7 ETM+ path/row 122/064 acquisition date 15/07/2001, band 5, 4, 2 was used to analyze the cover of land and the band 6 was used for the distribution of surface temperature was based on the pixels value. Results showed the value of surface temperature in Jakarta and surrounding area was between $15.07^{\circ} \mathrm{C}$ through to $33.28^{\circ} \mathrm{C}$. Location of heat island were in the centre Jakarta and north Jakarta, with the difference of the temperature as big as $3^{\circ} \mathrm{C}$ with the surrounding area. The land cover in this location were the housing building, the office complex, and the highway. Calculation of Spearman correlation value between the air temperature and surface temperature showed the existence of the positive correlation between two variables that it was demonstrated by the correlation index 0.6. From the regression equation we get the interpolated air temperature in Jakarta area.
\end{abstract}

\section{Intisari}

Pulau panas adalah suatu fenomena dimana suhu udara di suatu daerah lebih tinggi daripada suhu udara terbuka di sekitarnya. Daerah urban (perkotaan) sering mempunyai suhu lebih tinggi 1-6 derajat Celsius dibandingkan daerah sekitarnya (daerah pinggiran/ rural). Fenomena inilah yang dikenal sebagai "Pulau Panas Perkotaan" atau "Urban Heat Island" (UHI). Penelitian ini bertujuan untuk mengetahui pengaruh fenomena pulau panas perkotaan terhadap parameter iklim terutama suhu dan curah hujan di daerah Jakarta dan sekitarnya. Data yang digunakan pada tugas akhir ini adalah data curah hujan dan temperatur udara harian pada 5 stasiun pengamatan iklim, periode Januari 1991 - Desember 2001 sebagai data permukaan. Citra satelit Landsat 7 ETM+ path I row 122/064 akuisisi tanggal 15/07/2001 band 5,4,2 digunakan untuk menganalisis tutupan lahan dan band 6 digunakan untuk distribusi temperatur permukaan. Hasil menunjukkan nilai temperatur permukaan Kota Jakarta dan sekitarnya berada antara $15.07^{\circ} \mathrm{C}$ hingga $33.28^{\circ} \mathrm{C}$. Lokasi pulau panas perkotaan terdapat di daerah Jakarta pusat dan Jakarta utara, dengan perbedaan temperatur sebesar $3^{\circ} \mathrm{C}$ dibandingkan dengan daerah sekitarnya.Tutupan lahan yang terdapat di lokasi tersebut merupakan lahan terbangun yang terdiri dari bangunan perumahan, perkantoran, dan jalan raya. Perhitungan nilai korelasi Spearman antara data temperatur udara dari lima stasiun pengamatan dengan nilai piksel temperatur permukaan memperlihatkan adanya korelasi positif antara dua variabel tersebut yang ditunjukkan oleh indeks korelasi sebesar 0.6. Dengan persamaan regresi diperoleh citra temperatur permukaan di seluruh daerah pengamatan yang hasilnya menggambarkan bahwa lokasi pulau panas perkotaan sangat berpengaruh terhadap distribusi temperatur udara di atasnya.

Kata kunci : Urban Heat Island, Jakarta, Temperature

*UPT HB-BPPT, ${ }^{* *}$ Prodi Geofisika dan Meteorologi FITB - ITB, ${ }^{* * * G e o t e k ~ L I P I ~}$ 


\section{PENDAHULUAN}

Fenomena Heat Island ditandai dengan adanya suatu daerah yang memiliki suhu jauh lebih tinggi dibandingkan dengan daerah sekitarnya. suhu disini bisa meliputi suhu udara ataupun suhu permukaan lahan. Urban heat island atau pulau panas perkotaan dapat ditimbulkan oleh perubahan tata guna lahan (Mujiasih, 1998). Umumnya fenomena ini terjadi di perkotaan dengan bangunan atau gedung-gedung dan jaringan jalan yang rapat atau daerah industri yang padat yang dikelilingi pinggiran kota atau lahan bervegetasi. Yang patut dicermati adalah bahwa selain suhu, perbedaan juga terlihat pada curah hujan, curah hujan di daerah perkotaan cenderung lebih besar dibandingkan dengan daerah sekitarnya, mungkinkah heat island mempengaruhi curah hujan di perkotaan?.

Studi heat Island menggunakan data suhu udara dari stasiun permukaan telah banyak dilakukan oleh sejumlah ahli klimatologi. Namun disadari, bahwa hasilnya kurang memuaskan karena data suhu udara dari stasiun pengamatan permukaan sangat terbatas, sehingga hasilnya kurang akurat. Di sisi lain suatu studi terdahulu telah memanfatkan data satelit NOAA-AVHRR untuk mengkaji fenomena heat island meskipun dengan tingkat ketelitian yang masih kasar mengingat keterbatasan resolusi spasial data tersebut. Sedangkan penelitian mengenai dampak fenomena heat island terhadap parameter iklim, terutama curah hujan di indonesia umumnya, ataupun kota Jakarta khususnya, masih sangat terbatas. Oleh karena itu dalam paper ini penulis mencoba meneliti dampak fenomena heat island terhadap parameter iklim. Sedangkan untuk meneliti distribusi spasial suhu udara permukaan digunakan citra satelit Landsat-TM band 6.

\section{TUJUAN}

Penelitian ini bertujuan untuk mengetahui pengaruh fenomena pulau panas perkotaan terhadap parameter iklim terutama suhu dan curah hujan di daerah Jakarta dan sekitarnya.

\section{TEORI DASAR}

\section{Pulau Panas Perkotaan}

Heat island adalah suatu fenomena dimana suhu udara kota yang padat bangunan lebih tinggi daripada suhu udara terbuka di sekitarnya baik di desa maupun pinggir kota. Daerah urban (perkotaan) sering mempunyai suhu lebih tinggi 1-6 derajat Celsius dibandingkan daerah sekitarnya (daerah pinggiran/rural). Fenomena inilah yang dikenal sebagai "Pulau Panas Perkotaan" atau
"Urban Heat Island" (UHI). Fenomena ini pertama kali ditemukan seorang ahli meteorologi bernama Luke Howard pada tahun 1818. Pada umumnya suhu udara tertinggi akan terdapat di pusat kota dan akan menurun secara bertahap ke arah pinggir kota sampai ke desa. Suhu tahunan rata-rata di kota lebih besar sekitar $3^{\circ} \mathrm{C}$ dibandingkan dengan pingir kota (Landsberg,1981).

Gambar 1 memperlihatkan perbandingan suhu perkotaan dibandingkan dengan suhu pinggiran kota.

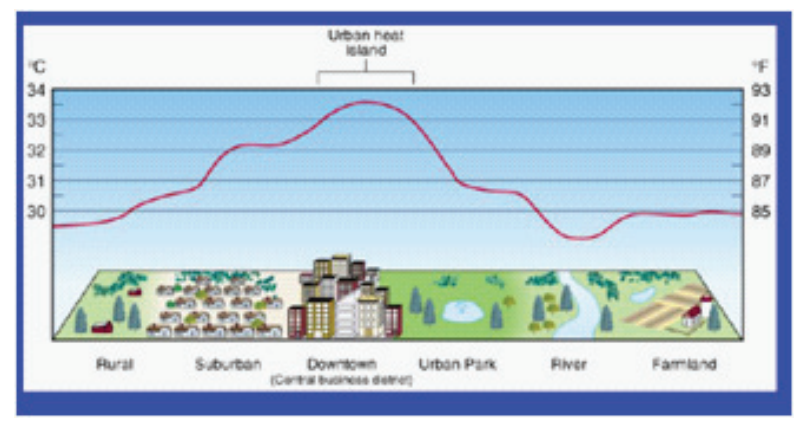

Gambar 1. Sketsa profil temperatur pulau panas perkotaan

sumber : http://www.atmosphre.mpg.de/enid

\section{Karakteristik Iklim di Wilayah Jakarta}

Jakarta beriklim tropis, dengan suhu tahunan rata-rata 27 C dengan kelembaban 80 - 90\%. Karena terletak di dekat garis khatulistiwa, arah angin dipengaruhi oleh angin musim. Angin musim barat bertiup antara November dan April, sedang angin musim timur antara Mei dan Oktober. Suhu sehari-hari kota Jakarta dipengaruhi angin laut yang nyaman karena di sepanjang pantai. Curah hujan rata-rata $2.000 \mathrm{~mm}$, curah hujan paling besar sekitar bulan Januari dan paling kecil pada bulan September (asriani, 2003).

\section{Konsep Dasar Penginderaan Jauh}

Pada umumnya dalam penginderaan jauh digunakan media gelombang elektromagnetik untuk berinteraksi dengan objek atau fenomena yang akan dikaji. Terdapat tujuh buah elemen terkait dalam penginderaan jauh, yaitu sumber energi yang akan menghasilkan gelombang elektromagnetik (EM); radiasi dan atmosfer; interaksi gelombang EM dengan target, perekaman energi oleh sensor; transmisi, penerimaan, dan proses gelombang EM; interpretasi dan analisis; serta aplikasi dari informasi yang diperoleh pada suatu masalah atau pengkajian informasi yang lebih mendalam mengenai suatu target di bumi.

\section{Metode Kuadrat Terkecil}

Data hasil pengukuran berfluktuasi mungkin disebabkan oleh galat acak dari sistem pengukuran atau kelakuan stokastik dari sistem yang diukur. 
Apapun alasannya, keperluan mencocokkan suatu fungsi pada data hasil pengukuran kerap kali terjadi. Dalam mencocokkan suatu fungsi pada data hasil pengukuran, semakin banyak titik datanya maka kecermatan kurva yang dicocokkan semakin tinggi. Pendekatan terbaik adalah meninjau fungsi dengan sedikit parameter bebas dan menentukan nilai parameter tersebut sedemikian sehingga simpangan fungsi dari titik-titik data sekecil mungkin. Peminimuman simpangan dicapai dengan menggunakan metode kuadrat terkecil.

\section{Uji Hipotesis Parameter Nonparametrik}

Setelah melakukan regresi linier, perlu adanya suatu uji kelayakan mengenai korelasi yang kita dapatkan. Uji kelayakan ini banyak macamnya. Pemakaiannya disesuaikan dengan karakteristik data dan kebutuhan. Data-data yang kita peroleh dari alam sebagian besar merupakan data yang tidak diketahui distribusinya. Oleh karena itu, uji hipotesis yang akan digunakan adalah Uji Hipotesis Non Parametrik. Dalam uji ini diperlukan suatu taraf keberartian dan hipotesa awal mengenai koefisien yang di uji. Terdapat banyak cara dan persamaan yang dapat digunakan untuk membuktikan hipotesa tersebut. Apabila sesuai, maka dinyatakan diterima atau hal yang di uji, dalam hal ini adalah koefisien dari regresi linier, layak untuk digunakan.

\section{DATA DAN METODOLOGI}

Dalam pengerjaaan tugas akhir ini, digunakan data-data sebagai berikut :

a. Data Klimatologi :

1. Data curah hujan harian 5 stasiun pengamatan iklim BMG, yaitu Curug Tangerang (6 $6^{\circ} 14^{\prime} 0.0^{\prime \prime} \mathrm{S}, 106^{\circ} 39^{\prime} 0.0^{\prime \prime}$ E), Darmaga (6 $6^{\circ} 30^{\prime} 0.0^{\prime \prime} \mathrm{S}, 106^{\circ} 45^{\prime} 0.0^{\prime \prime}$ E), Jakarta Observatorium (6 $6^{\circ} 10^{\prime} 0.0^{\prime \prime} S$, $\left.106^{\circ} 49^{\prime} \quad 0.0^{\prime \prime} \mathrm{E}\right)$, Halim Perdanakusumah (6 $6^{\circ} 16^{\prime} 0.0^{\prime \prime} \mathrm{S}, 106^{\circ}$ 53' 0.0" E), dan Cengkareng ( $6^{\circ} 7^{\prime} 0.0^{\prime \prime} \mathrm{S}$, $106^{\circ} 39^{\prime} 0.0$ " E) periode Januari 1991 Desember 2001.

2. Data Temperatur udara rata - rata harian 5 stasiun pengamatan iklim BMG, dengan stasiun dan waktu yang sama.

b. Data citra satelit :

Citra satelit Landsat 7 ETM+ path / row 122/064 yang direkam pada tanggal 15 - Juli - 2001, yang diperoleh dari Global Land Cover Facility (http://glcf.umiacs.umd.edu).
Diagram Metodologi

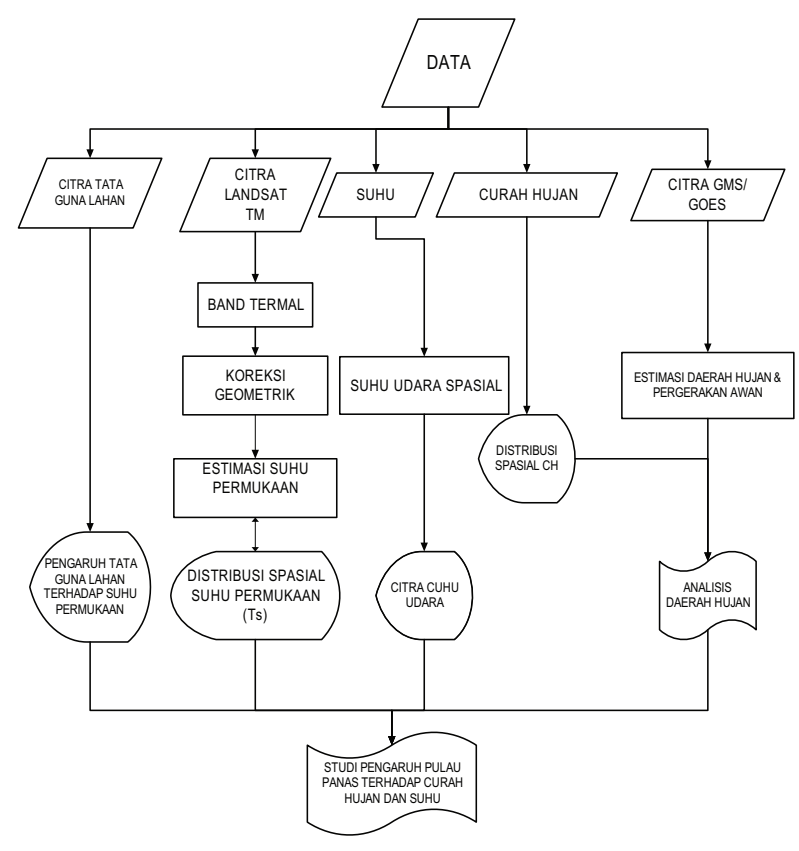

5. HASIL

\subsection{ANALISIS HASIL PERHITUNGAN TEMPERATUR PERMUKAAN}

Temperatur permukaan dipengaruhi oleh karakteristik masing - masing permukaan dan kondisi iklim mikro di daerahnya. Nilai temperatur permukaan Kota Jakarta dan sekitarnya seluruh grid berada antara $15.072^{\circ} \mathrm{C}$ hingga $33.279^{\circ} \mathrm{C}$. terlihat bahwa temperatur permukaan tertinggi terdapat di daerah pusat Kota Jakarta, atau lebih tepatnya berada pada koordinat $\left(6^{\circ} 29^{\prime} 30.8^{\prime \prime} \mathrm{S}\right.$, $\left.106^{\circ} 53^{\prime} 7.3^{\prime \prime} \mathrm{E}\right)$ dengan nilai $33.278595^{\circ} \mathrm{C}$. Nilai rata - rata temperatur permukaan yang didapat adalah $23.623^{\circ} \mathrm{C}$. Sedangkan untuk temperatur permukaan di Kota Bogor, Tangerang dan Bekasi didapat nilai yang lebih kecil daripada Kota Jakarta, ini menunjukkan bahwa Kota Jakarta memiliki koefisien termal yang lebih tinggi daripada kota kota disekitarnya. Citra satelityang menggambarkan temperatur permukaan diperlihatkan oleh gambar 5.1

\subsection{ANALISIS PULAU PANAS PERKOTAAN}

Pada gambar 5.2 terlihat bahwa lokasi pulau panas perkotaan terdapat di daerah pusat hingga utara Jakarta, dan tata guna lahan yang terdapat di lokasi tersebut merupakan lahan terbangun yang 
terdiri dari bangunan perumahan, perkantoran, dan juga jalan raya.

Gambar 5.3 menunjukkan lokasi yang memiliki nilai temperatur permukaan diatas $27.5^{\circ} \mathrm{C}$ (ditunjukkan oleh warna merah), sedangkan warna hitam menunjukkan nilai temperatur permukaan dibawah $27^{\circ} \mathrm{C}$. Nilai tersebut diambil dikarenakan definisi pulau panas perkotaan yang mengharuskan perbedaan suhu mencapai $1.5^{\circ}-3^{\circ} \mathrm{C}$ dibandingkan dengan daerah sekitarnya.

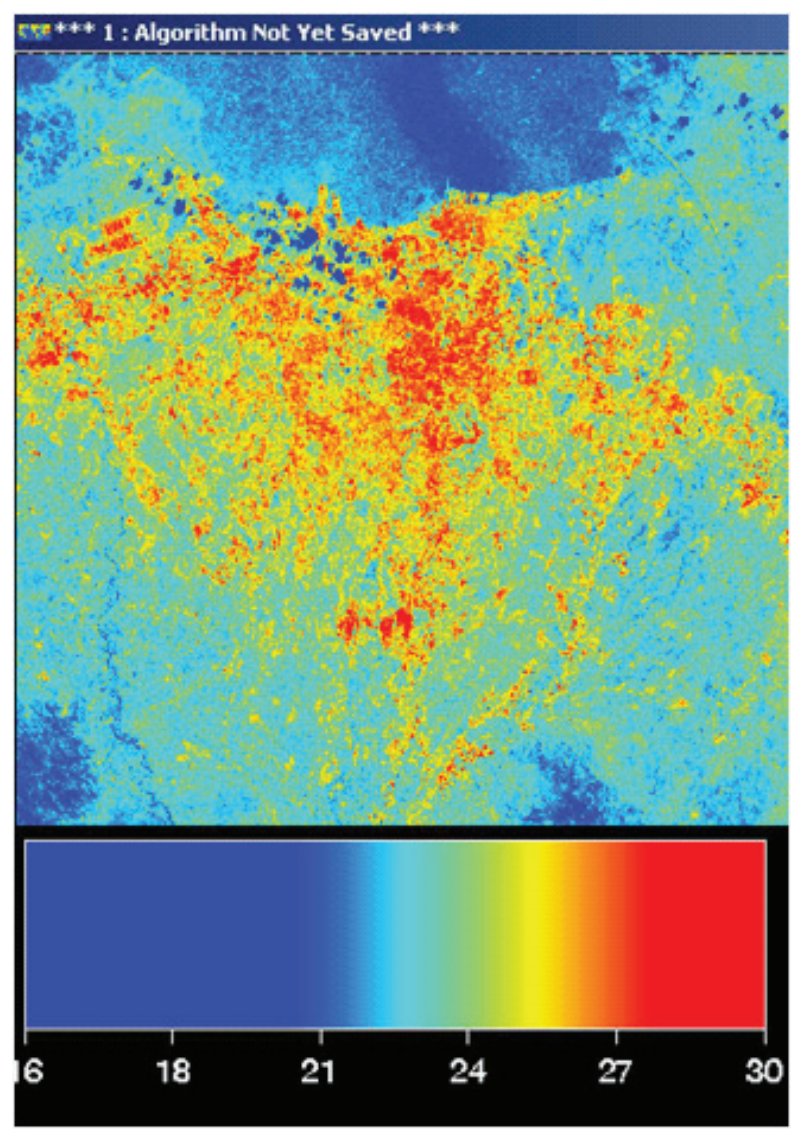

Gambar. 5.1. Distribusi spasial temperatur permukaan

\subsection{ANALISIS TEMPERATUR UDARA}

Gbr. 5.4 Distribusi temperatur udara koreksi Dari data temperatur udara tanggal 15 Juli 2001 dari lima stasiun pengamatan diperoleh distribusi spasial temperatur udara dalam bentuk isotherm untuk keseluruhan daerah pengamatan. Temperatur udara tertinggi $\left(28.6^{\circ} \mathrm{C}\right)$ terdapat pada daerah Kota Jakarta, kemudian menurun kearah selatan dan timur Kota Jakarta, yaitu Kota Bogor dan Tangerang, dan terus menurun sampai temperatur udara terendah di daerah pegunungan di sebelah barat dan timur Kota Bogor. Untuk mendapatkan hubungan antara temperatur permukaan dan temperatur udara, maka dilakukan proses overlay antara peta distribusi spasial temperatur permukaan dan peta distribusi spasial temperatur udara (gambar 5.4)

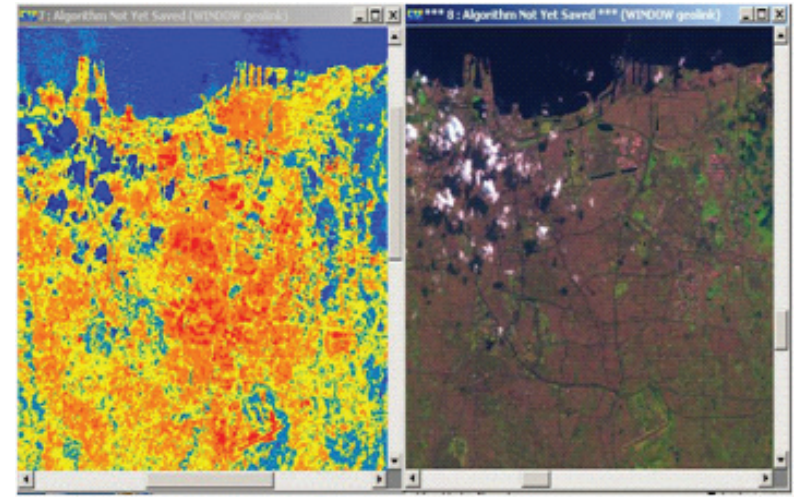

Gambar 5.2. Urban Heat Island dan kondisi tata guna lahan

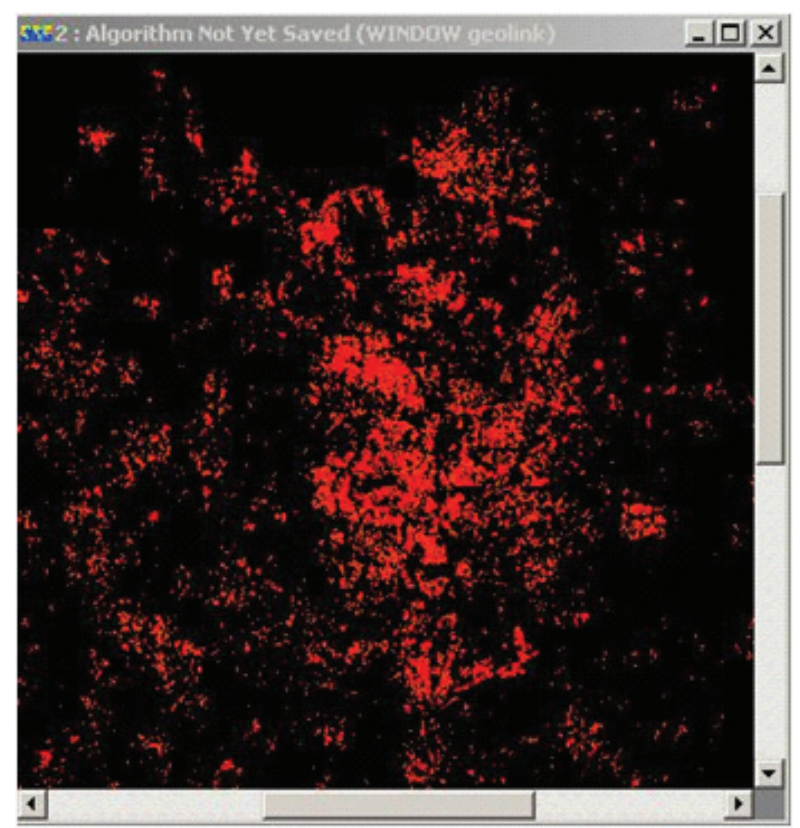

Gambar 5.3. Temperatur permukaan di atas $27.5^{\circ} \mathrm{C}$

Dengan menggunakan persamaan regresi $y=$ $1.0681 \mathrm{x}-3.8997$, yang didapat dari hasil regresi linier antara temperatur udara dan data temperatur permukaan dari citra satelit menggunakan metoda kuadrat terkecil, akan dicari nilai temperatur udara di lokasi yang tidak terlingkup oleh stasiun pengamatan, Gambar 5.5 merupakan citra temperatur udara hasil koreksi menggunakan persamaan regressi tersebut.

\subsection{ANALISIS HUJAN}

Pengkorelasian, data curah hujan dengan data temperatur pemukaan tidak dapat dilakukan, dikarenakan nilai curah hujan untuk waktu penelitian yaitu 15 Juli 2001 adalah nol/tidak ada hujan. 


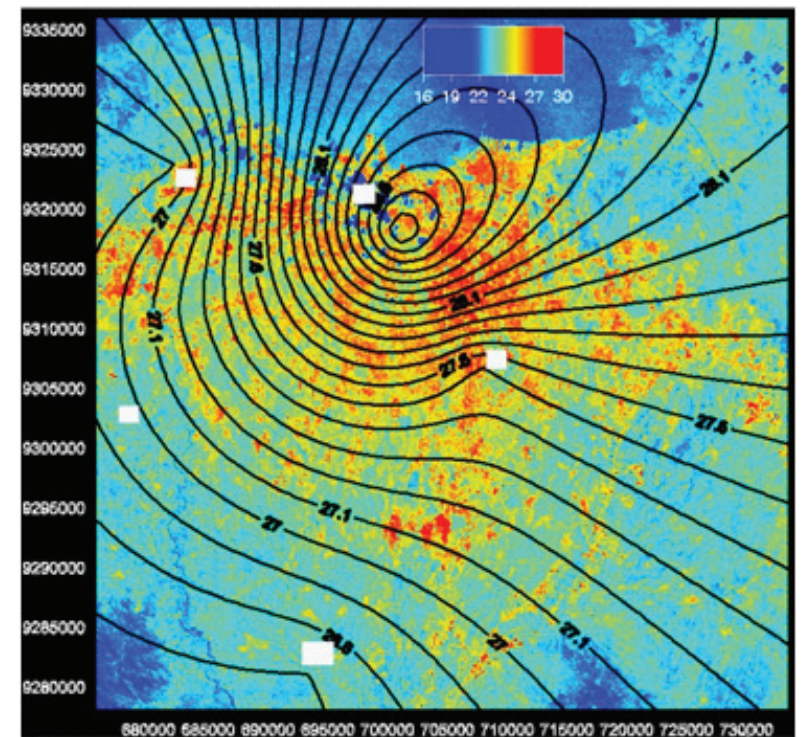

Gambar 5.4. Distribusi temperatur udara

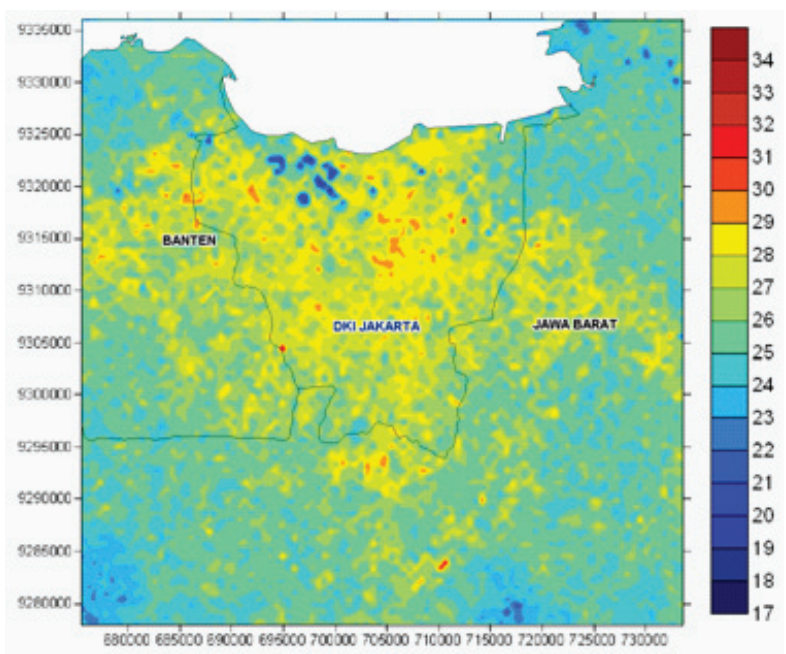

Gambar 5.5. Distribusi temperatur udara koreksi

\section{KESIMPULAN}

- Hasil proses citra landsat band 6 diperoleh bahwa distribusi temperatur permukaan di daerah DKI jakarta dan sekitarnya bervariasi antar $16-30{ }^{\circ} \mathrm{C}$, dengan lokasi pulau panas perkotaan terdapat di daerah Jakarta Utara, Jakarta Pusat.

- Hasil uji hipotesis nonparametrik rang spearman antara temperatur permukaan (Ts) dan temperatur udara (Tu) di lima titik pengamatan menghasilkan nilai $r=$ 0.675 . Syarat penolakan Ho adalah nilai $r<r a / 2$. Dari tabel dengan kepercayaan $95 \%$, diperoleh nilai $\mathrm{ra} / 2=0.900$ sehingga dalam hal ini Ho ditolak, dan hipotesis $\mathrm{Ha}$ diterima. Artinya ada kecenderungan nilai besar temperatur udara berpasangan dengan nilai besar temperatur permukaan, atau nilai temperatur udara yang kecil berpasangan dengan nilai temperatur permukaan.

- Persamaan regresi $y=1.0681 \mathrm{x}$ 3.8997 dapat digunakan untuk mendapatkan nilai temperatur udara di lokasi penelitian yang tidak terdapat data temperatur udara. Diperoleh citra temperatur udara yang dapat memberi informasi mengenai distribusi temperatur udara di daerah penelitian. Lokasi pulau panas perkotaan sangat berpengaruh terhadap distribusi temperatur udara di atasnya.

- Berdasarkan citra distribusi spasial temperatur permukaan dan citra komposit band 542 (tata guna lahan) diperoleh bahwa sebaran distribusi temperatur permukaan dipengaruhi oleh tata guna lahan, dimana tata guna lahan yang merupakan lahan terbangun, akan memiliki temperatur permukaan yang lebih tinggi dari temperatur permukaan di lahan terbuka.

- Korelasi antara temperatur Permukaan dan Curah hujan, tidak dapat dilakukan karena pada waktu penelitan tidak terdapat hujan.

\section{DAFTAR PUSTAKA}

Adiningsih, Erna S, et all, Januari 1994 Studi Pulau Panas Di Jakarta dan Sekitarnya Dengan Menggunakan Data Satelit, Majalah Lapan, No 68, 18 - 37

Asriani, Lisa, 2003, Penggunaan citra satelit dalam estimasi distribusi Evapotranspirasi spaisal (Studi Kasus Daerah Jakarta dan sekitarnya), Tugas Akhir, Institut Teknologi Bandung.

Bornstein, R., and Q. Lin, 2000: Urban heat islands and summertime convective thunderstorms in Atlanta: Three case studies. Atmos.Environ., 34, 507-516.

Canada Centre for Remote Sensing, 1998, Fundamental of Remote Sensing tutorial: Natural Resources Canada.

Huff, F. A., and S. A. Changnon, 1972: Urban effects on daily rainfall distribution. Preprints, Second National Conf. on Weather Modification, Santa Barbara, CA, Amer. Meteor. Soc., 215-220.

Landsberg, H. E., 1981: The Urban Climate. Academic Press, 275 pp.

Lillesand/Kiefer, 1997, Penginderaan Jauh dan Interpretasi Citra: Gajah Mada University Press. 
Mujiasih, S, 1998 , Studi perubahan tata guna lahan terhadap pembentukan pulau panas perkotaan studi kasus cekungan bandung, Tugas akhir, Institut Teknologi Bandung.

Mahardhika, R., 2004, Validasi model penyebaran karbon monoksida (CO) Kota Bandung berdasarkan distribusi temperatur menggunakan citra satelit Landsat 5 TM, Tugas akhir, Institut Teknologi Bandung.

Soenarmo, S. H., 1994, Penginderaan Jarak Jauh untuk Meteorologi-Oseanografi-Geofosika: Diktat Kuliah, Jurusan Geofisika dan Meteorologi, ITB.

Tjasyono, Bayong. 1999. Klimatologi Umum. Penerbit ITB. Bandung.
Tursilowati, 2005, Fenomena "Pulau Panas" Perkotaan, Lembaran Cakrawala, Harian umum Pikiran Rakyat Kamis, 24 Maret 2004.

Yang J, \& Wang J Q, Estimation of land surface temperature using Landsat 7 ETM+ Thermal infrared \& weather Station data, Departement of Natural Recources Science, University of Rhode Island Kingston, USA

http://en.wikipedia.org/wiki/uhi Urban Heat Island http://faculty.vassar.edu/lowry/corr_rank.html Rank-Order Correlation

http://ltpwww.gsfc.nasa.gov/IAS/handbook/ handbook_htmls/index.html Landsat 7 Science Data User Handbook 